\title{
Contribuições teóricas para o estudo do fenômeno urbano nos momentos iniciais de sua formação
}

\author{
Josarlete Magalhães Soares \\ Arquiteta e Urbanista, professora assistente I do Departamento \\ de Arquitetura e Urbanismo da Universidade Federal de Viçosa, \\ Universidade Federal de Viçosa, Departamento de Arquitetura \\ e Urbanismo, Campus UFV, CEP 36570-000, Viçosa, MG, (31) \\ 3899-1976, josarlete.soares@ufv.br
}

\section{Fernanda Borges de Moraes}

Arquiteta e Urbanista, professora adjunta I da Escola de Arquitetura da Universidade Federal de Minas Gerais, Universidade Federal de Minas Gerais, Escola de Arquitetura, Departamento de Urbanismo, Rua Paraíba, 697, sala 404a, Funcionários, CEP 30130-140, Belo Horizonte, MG, (31) 3409-8837, fernanda.borges.moraes@gmail.com

\section{Resumo}

Historicamente, as cidades têm desempenhado um papel importante no processo de estruturação da vida humana em sociedade, o que instiga o interesse em desvelar os agentes das intervenções sobre o território e os modos de fixação do povoamento e transformação do espaço natural. Com o intuito de orientar os pesquisadores interessados nesse assunto, o objetivo deste artigo é discutir algumas das abordagens utilizadas para a caracterização do meio urbano e apontar aspectos considerados fundamentais para o estudo do processo de formação das cidades. Nosso olhar se direciona fundamentalmente para o território brasileiro, buscando exemplos principalmente em Minas Gerais.

Palavras-chave: história urbana, formação de cidades, centralidade urbana.

campo de pesquisa em história urbana no Brasil vem se desenvolvendo de forma intensa nas últimas décadas. Historicamente, as cidades se constituem como espaços importantes de estruturação da vida humana em sociedade, instigando os estudiosos a se debruçarem sobre os mecanismos responsáveis pela sua produção. Esforços têm sido empreendidos no sentido de desvelar os agentes das intervenções sobre o território e o modo como ocorreram os processos de fixação da população e transformação do espaço natural. No entanto, a complexidade espacial e social que o fenômeno urbano abarca e a multiplicidade de abordagens que ele admite exigem do pesquisador uma visão holística sobre o tema, imprimindo a necessidade de direcionar a investigação em diversas linhas de estudo que, ao se complementarem, permitem um entendimento mais global sobre o processo de constituição e crescimento das cidades.

Tendo em vista essa complexidade multidisciplinar e de modo a orientar os pesquisadores interessados no estudo do processo de formação de núcleos urbanos, o objetivo deste artigo é discutir algumas das abordagens frequentemente utilizadas para a caracterização do meio urbano e apontar aspectos considerados fundamentais para o entendimento do processo inicial de constituição das cidades. Nosso olhar se direciona fundamentalmente para o território brasileiro, buscando exemplos principalmente em Minas Gerais. No contexto da formação territorial do Brasil, Minas apresentou certa peculiaridade. A descoberta do ouro provocou grandes alterações no quadro social e político- 
administrativo da América Portuguesa. A forma de extração do metal possibilitou o aparecimento de aglomerações humanas relativamente densas e a consequente formação de diversos núcleos urbanos. A cidade mineradora foi um fenômeno precoce e inédito no contexto da colonização, fixando-se antes mesmo que os mecanismos para o seu abastecimento fossem estruturados de forma eficiente. No entanto, ao longo dos séculos, novos fatores vieram a interferir sobre o modo de ocupação do território, imprimindo maior complexidade ao processo de formação da rede urbana mineira.

Ao longo das páginas seguintes, nossa análise será direcionada, inicialmente, para a investigação de alguns critérios historicamente adotados para a definição do meio urbano. Discutiremos, assim, a caracterização segundo parâmetros demográficos e administrativos, suas deficiências e sua validade. Na seqüência, faremos uma breve reflexão sobre as abordagens teóricas da relação (e diferenciação) entre campo e cidade. Por fim, apresentaremos alguns aspectos de manifestação da centralidade urbana, possivelmente os mais importantes para o processo de formação dos núcleos citadinos.

\section{A definição do meio urbano: critérios demográficos} sil, a definição de cidade tem um caráter eminentemente político-administrativo. Uma grande diversidade de abordagens sobre as noções de urbano e cidade pode ser encontrada, desde de autores como José Eli da Veiga (2002), que apontam a predominância de um modo de vida eminentemente rural para as populações das pequenas cidades brasileiras, como Roberto Luís de Melo Monte-Mór (2006), que defende a existência de um amplo processo de extensão dos padrões de comportamento urbano para além dos limites das cidades, atingindo inclusive o meio rural. Como - aprofundamento dessa discussão escapa ao objetivo deste artigo, em nossa bordagem os termos cidade e urbano serão utilizados como sinônimos, de modo a se referir à espacialidade caracterizada pela concentração humana num espaço relativamente reduzido e, consequentemente, às relações econômicas, sociais e simbólicas que essa concentração suscita.

No Brasil, desde o período colonial, o conceito de cidade sempre teve uma conotação oficial. Elas caracterizavam e ainda caracterizam o nível máximo da hierarquia administrativa municipal, sendo as sedes dos municípios integrantes do território hoje nacional. Entretanto, essa concepção baseada em critérios administrativos não manteve, ao longo da história, uma correspondência direta e inequívoca com as características de desenvolvimento dos núcleos urbanos (MORAES, 2006: 156-162). Tais critérios corresponderam e ainda correspondem, muitas vezes, a estratégias e decisões de cunho político.

Pedro P. Geider (1963: 8), discutindo a complexidade da adoção de padrões uniformes, aponta que, enquanto no Brasil o quadro urbano se caracterizava pela presença da autoridade administrativa, no México tal quadro se definia pela concentração mínima de 2.500 habitantes; nos Estados Unidos, além da autonomia administrativa e da concentração mínima de 2.500 habitantes, para a caracterização de um aglomerado urbano suas ruas deveriam ser pavimentadas; no Haiti, tais exigências eram ainda mais severas, pois também se consideravam critérios econômicos, como certas percentagens de distribuição da população ativa pelos setores secundário e terciário. Isso para o ano de 1958! Percebe-se, assim, a existência de uma variedade de critérios baseados principalmente na objetividade dos dados numéricos e estatísticos sobre a população urbana. Entretanto, devido às suas variações ao longo do tempo e de acordo com os diferentes países, todo um cuidado deve ser despendido na manipulação de tais números

Tomemos como exemplo alguns dados apresentados por Braudel (1995: 442-3). Segundo esse autor, para a caracterização de uma cidade na França dos anos de 1970, um aglomerado deveria possuir um mínimo de 2.000 habitantes; na Inglaterra, o número usado era de 5.000 . A estimativa de $25 \%$ de população urbana para a Inglaterra em 1801 passaria a 40\% caso se tomasse como base as comunidades acima de 2.000 habitantes. No caso da Alemanha, no final da Idade Média, foram identificadas 3.000 localidades com o direito de cidade adquirido, tais localidades contavam com uma população média em torno de 400 indivíduos. Percebe-se, assim, que as variações são grandes, expressando as particularidades de cada momento e contexto específico onde o fenômeno urbano se instalou.
Outro critério numérico é aquele relativo à densidade demográfica. Os cuidados aqui não devem ser menores, veja-se os números apresentados por Marcel Roncayolo (1986: 401): entre as cidades medievais da costa do mediterrâneo, Gênova atingiu, ao final da Idade Média, 900 habitantes por hectare; na mesma época, nas cidades da Espanha muçulmana esse número girava em torno de 60. No princípio do século XIX, Paris possuia entre 500 e 700 habitantes 
por hectare; a Paris de Haussmann, por volta de 1880, 290; e a Paris contemporânea oscila em aproximadamente 350. Esses índices representam uma média e como tal devem ser analisados. Nos anos de 1950, os bairros superpovoados do velho centro de Paris ultrapassavam 1.000 habitantes por hectare, enquanto os subúrbios burgueses oscilavam em torno de 200. A Londres de 1958 atingiu a já fraca densidade de 85 habitantes por hectare. Nos limites da grande Londres, menos de 50. Tais variações resultam das especificidades locais da aglomeração, das condições topográficas impostas ao crescimento urbano, das heranças históricas, dos modos de vida e das características das construções, dificultando sobremaneira as generalizações.

Desse modo, embora organismos internacionais venham tentando uma padronização das estatísticas, diversos autores apontam para a responsabilidade do pesquisador em desenvolver uma sensibilidade no tratamento de realidades específicas, relativizando os critérios de acordo com os tempos e espaços analisados. Uma definição que tome por base apenas dados numéricos de população pode excluir momentos e aspectos importantes principalmente no que se refere ao processo de gênese das aglomerações urbanas. Atento a isso, Braudel (1995: 442) deixa sua sugestão, e com ela concordamos:

É até estes limites inferiores que a história urbana deve estender seu estudo, pois as pequenas cidades (...) acabam por 'vencer' os seus campos circundantes, insuflam-Ihes 'consciência citadina' enquanto elas próprias são devoradas, submetidas pelos grandes aglomerados mais povoados e ativos do que elas.

Nesse sentido, os estudiosos que se interessarem em desvendar os processos primitivos de formação dos núcleos urbanos devem estar atentos para o fato de que a cidade é produto do crescimento e não de uma criação instantânea. Os processos de urbanização primitivos ganham, com o passar do tempo, elementos e dinâmicas novas que se associam de maneira dialética às marcas deixadas pelo processo original.

Cabe ressaltar, no entanto, que embora seja difícil estabelecer critérios relativos ao contingente populacional para aglomerações urbanas em formação, tais contingentes são de grande validade para se estabelecer níveis hierárquicos entre os centros. O tamanho da população é fator indicativo de um maior desenvolvimento do núcleo urbano, de sua maior atratividade e centralidade, o que corresponde a uma maior significância na estruturação dos fluxos econômicos e sociais de sua região. Desse modo, mais do que para a identificação dos núcleos urbanos, os dados populacionais nos servem, principalmente, para sua classificação quanto à centralidade e importância relativa no interior da rede urbana.

\section{A relação cidade-campo}

As caracterizações clássicas sobre o processo de gênese e evolução das cidades também passam por sua diferenciação em relação ao campo e a identificação de certas funções que o meio urbano assumiu ao longo desse processo. Sob o ponto de vista econômico, o aparecimento da cidade teria sido possibilitado pela produção de um excedente alimentar que permitiu a uma parte da população viver aglomerada, dedicando-se a atividades nãoagrícolas. Esse processo inaugurou uma divisão do trabalho entre campo e cidade e um processo de especialização de suas tarefas (SINGER, 2002: 7-27). Desse modo, a domesticação do cultivo de plantas e a criação de animais, a chamada Revolução Agrícola, ao possibilitar a produção desse excedente alimentar, permitiu também a formação do meio urbano. 0 campo precederia, assim, a cidade, sendo fator determinante para o seu aparecimento.

Entretanto, alguns autores têm questionado tal interpretação. Resgatando uma argumentação suscitada por Jane Jacobs, Edward Soja (2000) sustenta a hipótese de que o espaço da cidade pode ter se originado antes mesmo da Revolução Agrícola (ou, pelo menos, foi simultâneo a ela). Segundo esse autor, evidências arqueológicas têm indicado a existência, em certas regiões da Ásia, de aglomerações humanas relativamente densas compostas por comunidades de caçadores e coletores. Esse meio urbano primitivo desenvolveuse em tal magnitude que pressionou e acelerou a domesticação de plantas e animais, levando, assim, à Revolução Agrícola. Partindo desse princípio, Soja confere à cidade um potencial extra em relação a sua capacidade de organização das relações econômicas e sociais no território. O autor admite a existência de uma instância psicológica e social que levou e ainda leva os homens a viverem reunidos. A 
formação urbana teria, assim, uma sinergia própria, caracterizada pela tendência natural da sociedade humana à aglomeração e pela força que essa aglomeração, uma vez estabelecida, exerce sobre os processos sociais que ocorrem em seu interior e ao seu redor. O fenômeno urbano ganha, segundo essa perspectiva, características bastante instigantes para investigação, superando a mera oposição com o meio rural.

Ao longo do processo de colonização da América Portuguesa, essa relação campo-cidade não foi uniforme. Nos dois primeiros séculos, as cidades se constituíram como entrepostos comerciais, fazendo a ligação da produção rural aqui instalada com o mercado urbano europeu (REIS FILHO, 2000; 1857 e OLIVEIRA, 1982: 37-40). A exportação de produtos agrícolas (principalmente o açúcar) e a importação de produtos manufaturados estabeleceu, de certa forma, uma divisão do trabalho entre cidade e campo em nível internacional. A rede urbana formada apresentava polarizações muito fortes, correspondendo quase que exclusivamente à necessidade de apoio à agricultura de exportação. Composta por alguns centros regionais de fraca articulação entre si, construídos sob supervisão da Coroa, essa rede se completava com núcleos de menor importância, implantados, em geral, ao longo da costa. Tais centros configuravam-se como locais de encontro dos brancos-senhores e como ponto de instalação do aparato administrativo colonial. Materializavam, assim, o contado dos colonos com o sistema de colonização e, enquanto local de articulação entre a produção agro-exportadora e seus mercados, assumiram a função de sede do capital comercial. No entanto, o centro produtivo da economia estava no campo.

Esse padrão sofreu profundas alterações na região dos descobertos auríferos. A urbanização mineira, em seus primórdios, foi resultado da concentração populacional gerada pela atividade mineradora, que aglutinou os indivíduos nas áreas específicas onde se localizavam as lavras. Desse modo, o centro produtivo da economia mineira passou a ser o próprio meio urbano, pois era ele o local da produção. Gerando bens - no caso, ouro e diamantes - que, para a subsistência de seus habitantes, deveriam ser trocados por outros produtos, a cidade mineradora era um centro de produção e troca, gerando e organizando o espaço rural à sua volta (MONTE-MÓR, 2001).
Com o correr do século XVIII, a economia mineira ganhou maior complexidade. Concomitantemente à queda dos rendimentos da mineração, as atividades agropecuárias se fortaleceram e paulatinamente assumiram a posição de atividade econômica principal. A virada do século foi marcada, assim, por um processo de "ruralização". Segundo Alexandre Cunha (2007: 96-121), ocorreu uma inversão na lógica de produção do espaço em Minas Gerais. Se durante as primeiras décadas dos setecentos foi a precoce base urbana que impôs a criação do espaço rural - para o próprio abastecimento dos núcleos citadinos -, no século XIX é a expansão das atividades agropecuárias que irá desencadear a formação de novos centros urbanos, para comercialização dos gêneros produzidos e organização dos fluxos comerciais. "Do urbano como força primeira da dinâmica econômica no século XVIII passar-se-ia progressivamente para uma conjuntura em que o rural viria a ocupar essa posição" (Ibidem: 97). Nota-se, assim, a complexidade e o dinamismo que a relação campo-cidade assumiu no território mineiro.

Essa inversão da dinâmica econômica, no entanto, não significou uma retomada do padrão de urbanização até então característico da atividade agrícola na América Portuguesa. O quadro é novo e bastante diferenciado. Grande parte desse processo de expansão rural teve como base o mercado interno colonial. Além disso, a existência de uma cultura urbana já presente em Minas Gerais alterou o contexto de formação e desenvolvimento dos novos núcleos urbanos.

\section{A centralidade urbana}

Considerando a diversidade de aspectos que o processo de formação do meio urbano envolve, os estudos direcionados para esse tema devem atentar para algumas peculiaridades inerentes à cidade em sua essência, que tem levado, invariavelmente, à diferenciação em relação ao espaço natural. Tais peculiaridades são o desdobramento daquilo que poderia ser considerado como a característica primitiva e também a mais importante dos núcleos urbanos: sua centralidade. A cidade atrai por algum motivo: existência de um centro de culto, de um mercado permanente, concentração de órgãos de decisão e do aparato administrativo do Estado. Desde os momentos iniciais, tal aspecto se impõe 
e garante, assim, a permanência de determinadas funções urbanas no tempo e no espaço, sua radicação definitiva no ambiente (RONCAYOLO, 1986).

Na tentativa de sistematizar as diversas manifestações de centralidade, identificamos três aspectos que poderíamos considerar como determinantes dentro do processo de formação dos núcleos citadinos: o aspecto econômico, o político-administrativo e aquele referente às questões culturais e simbólicas. Embora diferentes cidades possam apresentar níveis variáveis de importância relativa entre tais aspectos, é a sua observação em conjunto que permite uma compreensão global do fenômeno urbano em suas mais diversas aparições, pelo menos no mundo ocidental.

A centralidade inerente ao aspecto econômico materializou-se de diversas formas ao longo do tempo e do espaço. Entretanto, nos momentos iniciais, sua principal manifestação se deu com a instalação do mercado. A cidade configurou-se como o local por excelência para a concentração do excedente coletivo e para a realização das trocas comerciais. A importância dessa função levou alguns autores a considerarem a cidade como um estabelecimento de mercado (WEBER, 1967). Tal característica, provavelmente, foi a que trouxe as maiores transformações para o meio urbano nos últimos dois séculos. Foi a partir da potencialização das atividades comerciais urbanas que a relação de complementaridade entre campo e cidade cedeu lugar a um processo de domínio da cidade sobre o campo, que se consolidou com o advento da produção industrial. A partir desse momento, a cidade experimentou um processo de intensificação de seu crescimento e de sua capacidade de organização da sociedade e da economia. Transformando-se no espaço privilegiado da produção, do consumo, das correntes de trocas e de circulação e do gerenciamento dos investimentos,

2 Essa dimensão do fenômeno urbano foi provavelmente uma das mais exploradas, tendo levado diversos autores a se debruçarem sobre a relação entre urbanização e industrialização. Citamos, a título de iniciação nessa temática: MONTE-MÓR, Roberto Luís. A Cidade e o Urbano. In: BRANDÃO, Carlos Antônio L. (org.). As cidades da Cidade. Belo Horizonte: Ed. UFMG, 2006. p. 185-197 mapeamos o processo de articulação do território da América Portuguesa a partir do estabelecimento dos fluxos de comércio entre as diversas partes desse território e a região das Minas. A dinâmica mercantil, tanto em nível regional quanto macrorregional, teve um papel importante na formação e consolidação de diversos assentamentos humanos e núcleos urbanos ao longo dos caminhos e, consequentemente, contribuiu para a ampliação e adensamento da rede urbana não só no território mineiro, mas em toda a América Portuguesa.

Nesse sentido, uma questão que deve ser considerada é a continuidade e a expansão, no território brasileiro, de uma rede de comércio realizada por meio das tropas de mulas e sua importância enquanto elemento balizador na formação dos assentamentos humanos. Conforme nos informa Braudel (1995: 459), "é também a geografia, de certo modo ligada à velocidade, ou melhor, à lentidão dos transportes da época, que explica as miríades de pequenas cidades". A necessidade de uma infra-estrutura de pousos que viabilizasse a circulação mercantil deixou suas marcas sobre o povoamento do território e sobre a conformação dos assentamentos humanos. A introdução de novos sistemas de transporte, principalmente o ferroviário, na segunda metade do século XIX, correspondeu a uma materialização das necessidades de fluxo comercial de uma nova atividade econômica - a lavoura de café para exportação -, no entanto, teve que interagir, ou se sobrepor, em alguns casos, à estrutura de caminhos já existente. E também a ferrovia, implantando estações não só nas áreas urbanas já existentes, mas em pontos estratégicos para escoamento da produção rural, foi um agente disseminador de novas centralidades.

Embora as questões relativas ao aspecto econômico sempre estivessem presentes, nunca estiveram sozinhas. A cidade, desde seus primórdios, foi também o local privilegiado onde o poder político se exerceu e onde os embates sociais se realizaram com maior força. Ao longo da história, a cidade coincidiu com o próprio Estado, em suas diversas manifestações, materializando não só o poder local e municipal, mas o próprio poder central (RONCAYOLO, 1986). Mesmo os aspectos de defesa militar são um desdobramento da representatividade urbana enquanto sede do poder de Estado. 
3 A primeira edição do clássico "Raízes do Brasil" foi publicada em 1936. Seu capítulo quarto, "O semeador e o ladrilhador", inaugurou uma ampla discussão empreendida ao longo do século XX (e ainda suscitada) sobre o caráter planejado (ou não) do urbanismo português na América.

4 Primeira edição de 1968.

5 A primeira edição em inglês foi publicada em 1979.

6 As escalas da hierarquia administrativa dos núcleos urbanos se expressavam, grosso modo, na elevação de um arraial à freguesia, de freguesia à vila e de vila à cidade. Os arraiais eram pequenos povoados, abrigando muitas vezes uma capela visitada esporadicamente por um sacerdote. As freguesias correspondiam às sedes de paróquia, servidas por um padre permanente. As vilas se diferenciavam pela autonomia administrativa, ou seja, pela presença de um conselho encarregado de administrar a gestão do território sobre sua jurisdição, a câmara. As cidades, por fim, possuíam as mesmas prerrogativas das vilas, sendo simbolicamente superiores por se fundarem em terrenos próprios. Ao longo dos séculos XVIII e XIX, as divisões políticas (vilas e cidades) e eclesiásticas (freguesias) se encontravam imiscuídas, do mesmo modo em que eram confusos os poderes do Estado e os da Igreja Católica. (MARX, 1991)
A implicação desse aspecto para a formação de núcleos urbanos no território brasileiro recebeu mais atenção por parte dos pesquisadores e também foi responsável pelo surgimento de discussões teóricas mais densas. A argumentação pioneira de Sérgio Buarque de Holanda (1995) comparando e contrapondo a regularidade da cidade da América Espanhola em relação à organicidade e ao "desleixo" da cidade da América Portuguesa, teve como principal instância de análise o papel (e o controle) dos Estados Metropolitanos sobre o processo de formação de suas cidades. A discordância de Nestor Goulart Reis Filho $(2000)^{4}$ em relação a esses apontamentos também se fundamentou numa análise sobre a atuação da Metrópole Portuguesa. Nestor Goulart procurou demonstrar como o desenvolvimento de nossas formações urbanas foi determinado pelas características do processo de colonização em seu esforço para controlar o povoamento e as atividades econômicas sobre o território: “...a organização da vida urbana, dos núcleos e dos principais aspectos destes, é o produto, em cada época, das condições históricas precedentes e da atuação dos agentes do processo de colonização e urbanização" (Ibidem: 197). A política metropolitana para nossas cidades se orientou, assim, de acordo com as especificidades que se impuseram à colonização. Elaborada ao longo dos dois primeiros séculos, tal política urbanizadora consolidou-se efetivamente no alvorecer do terceiro:

...ao terminar a segunda década do século XVIII estariam concluídas essas transformações, consolidadas as novas formas político-administrativas e definida a situação dos colonos, de tal modo que estariam maduras as condições para aplicação de uma política altamente centralizada, como a que caracterizou a ação da Metrópole, dessa época em diante. (Ibidem: 28)

Uma investigação sobre essa "política altamente centralizada" foi empreendida pela pesquisadora Roberta Marx Delson (1997) 5 . Em seu estudo ela delineia a constituição de um "projeto português" para a colonização da América a partir da implantação de arraiais e vilas planejadas no interior do território colonial ao longo dos setecentos:

Influenciados pela descoberta do ouro na década de 1690 e diretamente ameaçados, os administradores metropolitanos buscavam ansiosamente os meios de ampliar o seu controle; um sistema racional de distribuição de terras, combinado com a construção supervisionada de vilas, constituiu o processo pelo qual o interior podia ser protegido contra um crescimento independente e descontrolado. (Ibidem: 4)

A autora procurou enfatizar, assim, a importância das cidades (e das relações que elas geravam no interior da América Portuguesa) para o domínio do território e para o êxito da empresa colonial lusitana. Dentro dessa perspectiva, o papel da cidade enquanto materialização do poder de Estado foi, de certa forma, potencializado.

Relativamente ao território mineiro, destacamos pesquisas mais recentes, desenvolvidas por Cláudia Damasceno Fonseca (2003) e Fernanda Borges de Moraes (2006). Essas pesquisadoras apresentam perspectivas importantes sobre a maneira pela qual a Metrópole portuguesa exerceu sua ação sobre os núcleos urbanos em Minas Gerais. O modo como se constituíram as diversas instâncias da administração do território mineiro e a própria hierarquia administrativa ${ }^{6}$ de sua rede urbana expressou os processos ora de centralização, ora de descentralização do controle exercido pela Coroa sobre a capitania. Fonseca (2003) ainda nos traz informações relativas às orientações para implantação dos assentamentos urbanos e as preocupações com sua regularidade e salubridade. Tais preocupações se materializaram em ações constantes, embora pontuais, dos diversos agentes da Coroa presentes no território mineiro. Moraes (2006) nos mostra como a própria produção e representação cartográfica relativa à América Portuguesa e à capitania de Minas Gerais refletiu certos aspectos de sigilo e controle por parte de Portugal em relação ao território que progressivamente ia sendo desbravado, conhecido e ocupado. Todo esse processo não se fez, obviamente, sem embates e divergências com a população que se fixava e crescia. As imposições oficiais e as ações de transgressão estiveram igualmente presentes na dialética da ocupação do espaço.

A terceira implicação do caráter de centralidade inerente ao meio urbano se refere às questões culturais e simbólicas. Sua manifestação ocorreu e ainda ocorre de forma expressiva relativamente às evocações religiosas. No caso do Brasil, tal aspecto merece um olhar cuidadoso, uma vez que, durante todo o período colonial e mesmo durante 
7 Destacamos principalmente as reflexões realizadas nas obras: MARX, Murillo. Nosso chão: do sagrado ao profano. São Paulo: Edusp, 1988. 219p. e MARX, Murillo. Cidade no Brasil: Terra de quem? São Paulo: Nobel/ EDUSP, 1991.143p. o Império, Estado e Igreja Católica mantiveramse unidos.

Permaneceu esquecido, ou bastante desconsiderado, o fato de que, entre nós, até um século atrás, a Igreja esteve ligada ao Estado. Em conseqüência, os reflexos dessa realidade institucional não têm sido devidamente relacionados com a organização inicial, com a expansão ao longo de mais de quatrocentos anos e com a consolidação da nossa rede de cidades. (MARX, 1991: 17)

Murillo Marx foi provavelmente o principal pesquisador a estudar as implicações dessa união para a formação de nossos núcleos urbanos. Seus estudos destacam, sobretudo, as imprecisões entre o espaço sagrado, o espaço público e o espaço privado (ou, no caso do período colonial, espaço concedido) e suas consequências sobre a conformação do meio urbano na América Portuguesa ${ }^{7}$. Tomando como referência tais estudos, um fator fundamental e que fornece muitas pistas sobre os mecanismos de formação de nossos núcleos urbanos diz respeito ao papel da Igreja junto ao processo de fixação da população no espaço.

Unida ao Estado, a Igreja tornou-se também um agente ativo da colonização, materializando em suas ações as diretrizes de atuação da própria metrópole colonizadora. E ainda, segundo Murillo Marx (1991: 11), nos assuntos em que o Estado possa ter ficado ausente, a Igreja manteve-se atuante: "Enquanto nunca houve uma codificação colonial portuguesa, as normas e procedimentos eclesiásticos eram claramente estabelecidos. "E mais: "...às vagas determinações civis contrapunham-se recomendações expressas do clero que interferiam no desenho urbano." Desse modo, a interferência da I greja na implantação dos assentamentos humanos e na própria paisagem urbana foi significativa, tanto por meio da legislação eclesiástica quanto através da influência imediata que ela exerceu a partir de seu patrimônio construído: "A capela acolhe moradores em pequenas porções de sua gleba, torna-se instrumento de urbanização e cria uma nova paisagem." (Ibidem: 43)

Um aspecto que também ajuda a entender a importância da atuação da Igreja Católica sobre nossas formações urbanas é sua profunda ligação com o princípio da territorialidade (BADIE: 1995).
Sua estrutura territorial, materializada nas dioceses e paróquias, permitiu uma forte organização institucional repousada no dogma da centralidade e da representação. Esse fator garantiu, inclusive, a grande difusão da Igreja Católica pelo mundo e, particularmente, pelo território hoje brasileiro. É importante ressaltar que sua atuação, enquanto instituição, também se constitui como um dos aspectos da materialização das relações de poder no ambiente urbano, inclusive do próprio poder de Estado. Entretanto, a imposição desse domínio eclesiástico - e seu diálogo com outras formas de poder - só se tornou possível porque ele se exerceu sobre uma população cujo imaginário religioso e místico era muito presente.

Nesse sentido, o estudo desenvolvido pelo historiador Sérgio da Mata (2002) aponta alguns aspectos para os quais devemos manter olhares atenciosos. Estudando Minas Gerais nos séculos XVIII e XIX, esse autor procurou verificar de que maneira espaço e religião interagiram e de que modo características relativas ao catolicismo popular e suas representações configuraram-se como fatores determinantes para o processo de fixação dos primeiros assentamentos urbanos, ou protourbanos, como ele próprio sugere. Seu estudo descortina a maneira como o espaço recebeu e materializou aspectos rituais e de visão de mundo dos habitantes das Minas antigas. A manutenção do catolicismo como religião oficial após a independência e durante todo o período imperial, além da própria permanência do simbolismo que a religião representava - e, de certa forma, ainda representa -, contribuiu provavelmente para a manutenção da influência religiosa sobre a vida social e também sobre a paisagem urbana pelo menos até o início do século XX.

\section{Considerações finais}

Objeto de estudo multidisciplinar, a cidade é uma estrutura complexa e dinâmica. Ela é palco de uma gama variada de formas de interação entre os homens e, certamente, é a intervenção mais marcante construída pela sociedade humana sobre o espaço. Nesse sentido, entender o modo como essa estrutura surgiu, se consolidou e cresceu é também uma forma de tentar entender os mecanismos pelos quais a sociedade se relaciona e interage com o meio natural. 
Ao longo desse artigo, procuramos apresentar e problematizar diversas formas de abordagem e caracterização do fenômeno urbano nos momentos iniciais de sua formação, descortinando ao pesquisador interessado nesse assunto a variedade de caminhos pelos quais é possível trilhar. Desde os processos investigativos sobre os critérios de definição do meio urbano, passando pela dialética da relação cidade campo e finalmente discutindo a questão da centralidade urbana, procuramos apontar aqui três temas considerados centrais na construção de possíveis linhas de investigação sobre os processos de formação da cidade, sem esgotar, obviamente, o amplo leque de possibilidades de abordagem sobre o assunto. Cabe destacar, no entanto, a importância de se direcionar um olhar atento relativamente aos aspectos econômicos, políticos e simbólicos e, principalmente, o modo como a centralidade urbana se manifesta a partir deles. Identificar tais manifestações de centralidade e entender como elas dinamizam o meio à sua volta nos permite uma compreensão mais sofisticada e também mais ampla sobre o processo de gênese das aglomerações urbanas.

Por fim, no que se refere ao quadro urbano brasileiro, a investigação sobre esse três temas ajuda a entender não só os processos primitivos de formação de nossas cidades, mas suscita questionamentos sobre a própria continuidade de crescimento das aglomerações urbanas, permitindo identificar problemáticas inclusive na contemporaneidade. Afinal, a discussão sobre os critérios de definição do meio urbano no Brasil ainda são objeto de crítica por parte dos pesquisadores, assim como permanecem em franca transformação na atualidade as relações econômicas, sociais e culturais entre cidade e campo. Quanto à questão da centralidade, tema de natureza complexa desde sempre, os estudos sobre as dinâmicas urbanas contemporâneas apontam para um incremento de tal complexidade, descortinando a multiplicidade de centralidades que hoje proliferam na cidade e as diversas formas de interação entre elas. Desse modo, se tais aspectos ajudam a entender os processos de gênese urbana, eles também fornecem linhas de investigação importantes (e polêmicas) sobre a cidade atual.

\section{Referências bibliográficas}

BADIE, Bertrand. Capítulo 2: A lenta ascensão do princípio da territorialidade. In: O fim dos territórios. Ensaio sobre a desordem internacional e sobre a utilidade social do respeito. Lisboa: Instituto Piaget, 1995.
BRAUDEL, Fernand Capítulo 8: As Cidades. In: Civilização material, economia e capitalismo. Séculos XV-XVIII. São Paulo: Martins Fontes, 1995. v.1. (As Estruturas do Cotidiano: O Possível e o Impossível)

CUNHA, Alexandre Mendes. Minas Gerais, da capitania à província: elites políticas e a administração da fazenda em um espaço em transformação. Tese, Doutorado em História, Universidade Federal Fluminense. Niterói: 2007

DELSON, Roberta Marx. Novas vilas para o Brasil-Colônia: planejamento espacial e social no século XVIII. Brasília: Alva/CIORD, 1997.

FONSECA, Cláudia Damasceno. Des terres aux villes de I'or: pouvoirs et territoires urbains au Minas Gerais, Brésil, XVIIle siècle. Paris: Centre Culturel Calouste Gulbenkian; Lisboa: Fundação Calouste Gulbenkian, 2003.

GEIDER, Pedro P. Evolução da rede urbana brasileira. Centro Brasileiro de Pesquisas Educacionais/Instituto Nacional de Estudos Pedagógicos/Ministério da Educação e Cultura: Rio de Janeiro, 1963

HOLANDA, Sérgio Buarque de. Capítulo 4: O semeador e o ladrilhador. In Raízes do Brasil. 26 ed. São Paulo: Companhia das Letras, 1995.

IBGE - Instituto Brasileiro de Geografia e estatística. Conceitos. s/d. Disponível em <http://www. ibge.gov.br/home/estatistica/populacao/criancas_adolescentes/notastecnicas.pdf>, acesso em $13 / 05 / 2011$

MARX, Murillo. Cidade no Brasil: Terra de quem? São Paulo: Nobel/EDUSP, 1991

Nosso chão: do sagrado ao profano. São Paulo: Edusp, 1988

MATA, Sérgio da. Chão de Deus: Catolicismo popular espaço e proto-urbanização em Minas Gerais, Brasil. Séculos XVIII-XIX. Berlin: Wissenschaftlicher Verlag Berlin, 2002.

MONTE-MÓR, Roberto Luís de Melo. A Cidade e o Urbano. In: BRANDÃO, Carlos Antônio L. (org.). As cidades da Cidade. Belo Horizonte: Ed. UFMG, 2006.

Gênese e estrutura da cidade mineradora. Belo Horizonte: CEDEPLAR/FACE/UFMG, 2001. 14p. (Texto para discussão; 164). Disponível em <http:// www. cedeplar.ufmg.br/pesquisas/td/TD\%20164. pdf>, acesso em 15/10/2008.

MORAES, Fernanda Borges de. A rede urbana das Minas coloniais: na urdidura do tempo e do espaço. Tese, Doutorado em Arquitetura e Urbanismo, Universidade de São Paulo. São Paulo, 2006. 3v.

OLIVEIRA, Francisco de. "O Estado e o urbano no Brasil". Espaço e Debates. São Paulo, n. 6, p. 37-54, 1982.

REIS FILHO, Nestor Goulart. Contribuição ao estudo da evolução urbana do Brasil (1500/1720). 2 ed. rev. e ampl. São Paulo: Pini, 2000.

RONCAYOLO, Marcel. Cidade. In: ROMANO, Ruggiero (org.). Região. Enciclopédia Einaudi. Lisboa: Casa da Moeda, 1986. v. 8 
SANTOS, Milton. A cidade como centro de região. Definições e métodos de avaliação de centralidade. Salvador: Livraria Progresso, 1959.

SINGER, Paul. Economia Política da Urbanização. 2 ed. São Paulo: Contexto, 2002. 155p.

SOJA, Edward. Putting Cities First. In:__. Postmetropolis: Critical Studies of Cities and Regions. Oxford: Backwell, 2000.

VEIGA, José Eli da. Cidades imaginárias: o Brasil é menos urbano do que se calcula. Campinas-SP: Autores Associados, 2002.

WEBER, Max. Conceitos e categorias da cidade. In: VELHO, Otávio Guilherme. O fenômeno urbano. Rio de Janeiro: Zahar, 1967. 


\title{
Theoretical contributions to research on the urban phenomenon in the early stages of its formation
}

Josarlete Magalhães Soares, Fernanda Borges de Moraes

\begin{abstract}
Historically, the city has played an important role in the structuring of human life in society, arousing interest in unveiling the agents of the interventions on the territory and the methods of population settlement and transformation of the space. In order to guide researchers interested in this subject, this paper aims to discuss some of the approaches used to characterize the urban environment and point out aspects considered essential to study the process of cities formation. Our focus is directed primarily to the Brazilian territory, seeking examples mainly in Minas Gerais.
\end{abstract}

Keywords: urban history, cities formation, urban centrality.

\section{Aportaciones teóricas al estudio del fenómeno urbano en las primeras etapas de su formación}

Josarlete Magalhães Soares, Fernanda Borges de Moraes

\section{Resumen}

Históricamente, las ciudades han desempeñado un papel importante en la estructuración de la vida humana en la sociedad, lo que despierta interés en la revelación de los agentes de las intervenciones sobre el territorio y las formas de fijación de la población y la transformación del espacio natural. Con el fin de guiar a los investigadores interesados en este tema, el objetivo de este trabajo es discutir algunos de los métodos utilizados para caracterizar el ambiente urbano y señalar los aspectos considerados esenciales para estudiar el proceso de formación de las ciudades. Nuestra atención se dirige principalmente al territorio brasileño, con ejemplos principalmente de Minas Gerais.

Palabras clave: historia urbana, la formación de las ciudades, la centralidad urbana. 